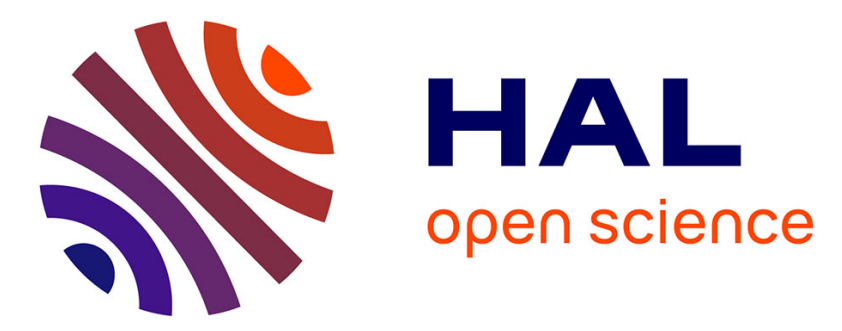

\title{
Parental calculation of paediatric paracetamol dose: a randomised trial comparing the Parental Analgesia Slide with product information leaflets
}

Richard Charles Hixson, Uwe Franke, Rohit Mittal, Mika Hamilton

\section{- To cite this version:}

Richard Charles Hixson, Uwe Franke, Rohit Mittal, Mika Hamilton. Parental calculation of paediatric paracetamol dose: a randomised trial comparing the Parental Analgesia Slide with product information leaflets. Pediatric Anesthesia, 2010, 20 (7), pp.612. 10.1111/j.1460-9592.2010.03332.x . hal-00552646

\author{
HAL Id: hal-00552646 \\ https://hal.science/hal-00552646
}

Submitted on 6 Jan 2011

HAL is a multi-disciplinary open access archive for the deposit and dissemination of scientific research documents, whether they are published or not. The documents may come from teaching and research institutions in France or abroad, or from public or private research centers.
L'archive ouverte pluridisciplinaire HAL, est destinée au dépôt et à la diffusion de documents scientifiques de niveau recherche, publiés ou non, émanant des établissements d'enseignement et de recherche français ou étrangers, des laboratoires publics ou privés. 


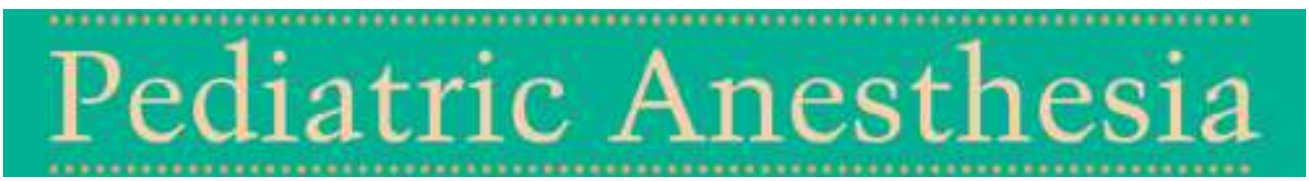

\section{Parental calculation of paediatric paracetamol dose: a randomised trial comparing the Parental Analgesia Slide with product information leaflets}

\begin{tabular}{|r|l|}
\hline Journal: & Pediatric Anesthesia \\
\hline Manuscript ID: & PAN-2009-0508.R1 \\
\hline Manuscript Type: & Original Paper \\
\hline Date Submitted by the \\
Author: & $21-J a n-2010$ \\
\hline Complete List of Authors: & $\begin{array}{l}\text { Hixson, Richard; Darlington Memorial Hospital, Anaesthesia } \\
\text { Franke, Uwe; James Cook University Hospital, Anaesthesia } \\
\text { Mittal, Rohit; James Cook University Hospital, Anaesthesia } \\
\text { Hamilton, Mika; Freeman Hospital, Anaesthesia }\end{array}$ \\
\hline Key Words: & Pediatric, Analgesia, Administration, Parents \\
\hline
\end{tabular}

\section{scholarONE \\ Manuscript Central}




\title{
Parental calculation of paediatric paracetamol dose: a randomised trial comparing the Parental Analgesia Slide with product information leaflets
}

Evaluation of the Parental Analgesia Slide

\author{
R. Hixson, ${ }^{1}$ U. Franke, ${ }^{2}$ R. Mittal, ${ }^{3}$ and M. Hamilton ${ }^{4}$ \\ ${ }^{1}$ Dr Richard Hixson, Department of Anaesthesia, Darlington Memorial Hospital, \\ Hollyhurst Road, Darlington. DL3 6HX, UK. 01325743327. \\ Richard.Hixson@cddft.nhs.uk
}

${ }^{2}$ Dr Uwe Franke, Department of Anaesthesia, James Cook University Hospital, Marton Road, Middlesbrough. TS4 3BW, UK. 01642850850.

ufranke@doctors.org.uk

${ }^{3}$ Dr Rohit Mittal, Department of Anaesthesia, James Cook University Hospital, Marton Road, Middlesbrough. TS4 3BW, UK. 01642850850.

drrohitmittal@yahoo.co.uk

${ }^{4}$ Dr Mika Hamilton, Department of Anaesthesia, Freeman Hospital, High Heaton, Newcastle upon Tyne. NE7 7DN, UK. 0191233 6161.mikahamilton@hotmail.com

Correspondence to: Dr Richard Hixson, Department of Anaesthesia, Darlington Memorial Hospital, Hollyhurst Road, Darlington. DL3 6HX, UK. 
Telephone: 01325743327

Fax: $\quad 01325743875$

Email: $\quad$ Richard.Hixson@cddft.nhs.uk

Abstract word count: $\quad 245$

Main text word count: $\quad 2687$

Trial registration: clinicaltrials.gov NCT00765609 


\section{ABSTRACT}

Objectives: To compare the ability of parents to calculate and demonstrate the correct paracetamol (acetaminophen) dose, interval and frequency for their child when using either product information leaflets or the Parental Analgesia Slide.

Background: Prescribing information provided with over-the-counter medication may be a source of confusion for parents delivering analgesics to children at home. Accurate administration is essential to ensure safe and effective treatment of children's pain or fever. The Parental Analgesia Slide is a new device developed with the objective of improving parental dosing accuracy.

Methods: In this prospective, randomised study, 160 parents accompanying children aged between one and 13-years-old were randomly allocated to complete a paracetamol dose calculation and administration questionnaire using one of two sources of prescribing information. Absolute percentage dose error and the number of correct dosage intervals, frequencies and demonstrated drug volumes were compared.

Results: Use of the Parental Analgesia Slide resulted in a reduction in the absolute percentage dose error from a median of 33.3 to $0 \%(\mathrm{p}<0.001)$ and an increase in the number of correct dosage intervals and frequencies ( 59 to $70 / 80, p=0.046$ ). There was no difference in the number of correctly demonstrated drug volumes $(p=0.082)$ despite a greater number of parents opting to use an oral syringe rather than a dosing spoon when using the Slide ( 24 to $44 / 80, p=0.002$ ). 
Conclusions: The Parental Analgesia Slide resulted in improved parental ability to calculate paracetamol dose, interval and frequency whilst preserving their ability to demonstrate an accurate drug volume.

Keywords: pediatric, analgesia, administration, parents. 


\section{INTRODUCTION}

There is continuing evidence that children do not receive adequate postoperative pain relief following discharge from hospital (1-3). Under treatment of pain is unacceptable, has undesirable long-term effects $(4,5)$ and exposes the child to the risk of an adverse drug reaction without the benefit of receiving a potentially effective dose (6). Misinterpretation of prescribing information may result in both under and overdose that can lead to serious adverse outcome including death (7-9).

Deciding on the correct analgesic formulation, dose, interval and frequency for a child receiving pain relief at home can be challenging for parents. Precise individual guidance is not readily available with requirements changing throughout childhood. The majority of therapeutic errors resulting in a major event or death arise after domestic use with paracetamol (acetaminophen) the drug most commonly implicated (10).

The Paediatric Analgesia Wheel improved the prescribing accuracy of hospital doctors when assessed in both a simulated and clinical environment $(11,12)$. It is proposed that the Parental Analgesia Slide (figure 1), a simplified version of the hospital based device, may improve the accuracy of paracetamol administration by parents when compared to use of product information leaflets.

\section{METHODS}




\begin{abstract}
A prospective, randomised, questionnaire-based study was designed to compare parentally calculated and 'ideal' doses of paracetamol when using either product information leaflets or the Parental Analgesia Slide (also referred to as the 'Slide'). For the purpose of this study an ideal dose was defined as a dose calculated by weight, easily administered with an oral syringe and within marketing authorisation.
\end{abstract}

The Slide provides parents with pre-calculated drug administration information for children between one and 13-years-old (10 to $44 \mathrm{~kg}$ ). Precise age and weight specific volumes for paracetamol (120 $\mathrm{mg}$ and $250 \mathrm{mg} / 5 \mathrm{ml})$ and ibuprofen $(100 \mathrm{mg} / 5 \mathrm{ml})$ are displayed to an accuracy of $0.5 \mathrm{ml}$ reflecting the smallest division on the oral syringe used in this study. Instructions for use, choice of formulation, dose interval and frequency are displayed on the outer sleeve. Alignment of the Slide is primarily determined by weight with clear instructions on correction for overweight children.

\title{
Participants and interventions
}

\author{
Volunteers were sought from parents accompanying children attending hospital. \\ Parents who had professional knowledge of prescribing or dispensing medicines, \\ those who had been advised on a dose of paracetamol for their child as part of their \\ current hospital episode or parents accompanying children under one-year or over 13- \\ years-old were excluded.
}

Parents were required to read a participant information sheet which described the research background and requirement for volunteers to complete a short test. Following an opportunity to ask questions, written informed consent was obtained. 
Parents were randomly assigned to one of two groups and instructed to record the formulation and volume of paracetamol to administer using their child's age; hospital measured weight and provided prescribing information. Parents in group 1 were required to use unmodified paracetamol 120 and $250 \mathrm{mg} / 5 \mathrm{ml}$ product information leaflets (Calpol, McNeil Ltd, Maidenhead, Berkshire, UK) which present a range of permissible paracetamol volumes for different age groups (e.g. 1 to 2 large $5 \mathrm{ml}$ spoonfuls of $120 \mathrm{mg} / 5 \mathrm{ml}$ paracetamol suspension for children 1 to 6 years old). Parents in group 2 were required to use the Slide which presents precise age and weight specific paracetamol volumes with instructions for use provided on the outer sleeve. Parents completed the test using only one method without assistance and cross-over between groups did not occur.

Parents were also required to state the maximum number of times per day they would administer the dose, the shortest interval between doses in hours and finally to demonstrate their recorded paracetamol volume using either a dosing spoon or a $5 \mathrm{ml}$ oral syringe (Exacta-Med ${ }^{\circledR}$, Baxa Ltd, Berkshire, UK). Parents in both groups were free to choose either measuring device. The dosing spoon, distributed with over-thecounter boxes of Calpol, permits drug administration to accuracy of $2.5 \mathrm{ml}$. The oral syringe, which can be purchased by the public or supplied to parents by healthcare professionals, permits drug administration to accuracy of $0.5 \mathrm{ml}$. Parents who had used the Slide were asked to comment on four statements using a Likert rating scale of one to five, strongly disagree to strongly agree.

\section{Objectives and outcomes}


The primary objective was to compare the two groups with respect to absolute percentage dose error (PDE) calculated from the difference between the parental and ideal doses. The secondary objectives were to compare the data relating to recorded dose interval (in hours), frequency (maximum number of doses per day) and demonstrated drug volume.

The null hypothesis for the primary objective was that there would be no difference in absolute PDEs when comparing the two groups. The alternative hypothesis was that one method would be superior with a significant difference in absolute PDE. The null hypothesis for the secondary objectives was that there would be no difference in the number of correct answers when comparing the two groups. The alternative hypothesis was that one method would result in a greater number of correct answers for the recorded variables.

Sample size calculation, randomisation, blinding and statistical methods

Pilot data predicted that 80 parents were required in each group to have an $80 \%$ chance of detecting a 10\% difference in absolute PDE using a Mann-Whitney U test with $\mathrm{p}=0.05$. A total of 160 participant instruction and answer sheets were labelled either 'product information leaflet' or 'Slide' as defined by electronic randomisation restricted to provide equal numbers in both groups. The participant instruction and answer sheets were sealed in identical unmarked envelopes and distributed to data collection researchers. In order to prevent bias, data collection researchers were blinded to envelope contents and explained both methods of calculating drug volume to parents prior to the envelopes being opened. 
Data entry and analysis was undertaken by a researcher blinded to the completion method. Drug volumes were converted to dose dependent on formulation and compared to the ideal dose calculated for each child. The difference between parental and ideal dose was expressed as the percentage dose error to compensate for the effect of dose error magnitude across different age and weight groups. To avoid the assumption that dose errors would be normally distributed, PDEs were converted to absolute values and dose error magnitude compared using the Mann-Whitney U test.

Dose intervals and frequencies were marked as either correct or incorrect as defined by the paracetamol summary of product characteristics. The demonstrated drug volume was compared to the recorded parental volume and marked as either correct or incorrect. The numbers of correct answers in the two groups were compared using the chi-squared test.

Ethics approval granted by the National Research Ethics Service (Sunderland, UK) January $5^{\text {th }} 2009$, REC reference number 08/H0904/93.

\section{RESULTS}

A total of 80 parents without exclusion were recruited into each group between January $6^{\text {th }}$ and March $31^{\text {st }} 2009$. All parents completed the questionnaire with zero withdrawals during data collection. Figure 2 shows PDE distribution before conversion to absolute values with the summary of primary data analysis shown in table 1. There was a reduction in absolute PDE in group 2 when using the Slide with 
median dose error decreasing from 33.3 to $0 \%(p<0.001,95 \%$ confidence interval 29.2 to 16.7$)$.

Table 1 also shows secondary and additional data analysis. Group 2 demonstrated an increase in correctly recorded dose intervals and frequencies to 70 compared with 59 in group $1(\mathrm{p}=0.046)$. The number of parents who chose an oral syringe to demonstrate drug volume increased from 24 in group 1 to 44 in group $2(p=0.002)$. There was no difference in the number of correctly demonstrated drug volumes between the two groups $(\mathrm{p}=0.082)$.

Table 2 shows the distribution of parental doses against children's weights with 34 parents failing to correctly align the Slide for the age and weight of their child. There was no difference $(p=0.183)$ in the number of parents who failed to correctly align the Slide for children whose actual body weights were not ideal $(27 / 56)$ when compared with children whose weights were considered ideal for age (7/24).

All parents in group 2 provided responses to the four statements with at least 70 of 80 parents agreeing with statements one, two and four. There were 58 of 80 parents who agreed with statement three which related to feeling more comfortable when using the Slide (figure 3).

\section{DISCUSSION}

Parental use of the Slide resulted in a decrease in absolute percentage dose error and an increase in the number of correct dosage intervals and frequencies when compared 
to use of product information leaflets. There was no difference in the number of correctly demonstrated drug volumes between the two groups despite a greater number of parents choosing to use an oral syringe in group 2.

The strength of this study lies in the simulation of a real life scenario with parents recruited from those accompanying children receiving medical attention in hospital. The product information leaflets represent information available to parents at home and therefore the comparison is between the Slide and actual domestic prescribing information. The main study limitation is that clinical outcome was not assessed. Use of this device will only be of benefit if an improvement in pain scores, a decrease in adverse drug events or a reduction in demand on healthcare resources can ultimately be demonstrated. A second limitation relates to potential bias since the doses on the Slide are identical to those defined as ideal. However, since the Parental Analgesia Slide is unfamiliar to parents, device functionality and the clarity of presented data is ultimately being assessed with prescribing accuracy the objective measure.

Parents often find difficulty calculating or administering accurate drug doses to their children $(2,3,13-17)$ with up to $62 \%$ failing to deliver the correct dose of paracetamol in the domestic setting (14). Parental knowledge of potential side effects associated with children's over-the-counter medication is limited $(3,16,17)$ and hepatotoxicity following domestic administration of paracetamol has been reported $(7-9,18)$. Accidental overdose in children may be caused by caregivers failing to correctly interpret instruction labels, using inappropriate preparations or incorrect measuring devices $(8-10,13-15,19)$. It has been shown that parents of all educational backgrounds have difficulty interpreting prescribing information supplied with over- 
the-counter medication (20) and confusion may lead to some parents simply guessing a dose (14). Distrust of higher doses recommended by hospital staff may occur (3) with evidence suggesting an overall tendency of parents to under dose their children at home $(2,13,14,16)$. It is proposed that the improvement in dose accuracy seen in group 2 is a result of pre-calculated ideal doses, clearly presented as age and weight specific drug volumes which circumvent the need for parents to interpret product information leaflets at the point of drug delivery.

Parental errors may occur with respect to drug interval and frequency $(2,10,15,18)$ and although less common than errors associated with dose $(14,16)$ may be an under recognised cause of treatment failure in children (15). In contrast to a previous study of hospital doctors using the more complex Paediatric Analgesia Wheel (11) this study demonstrated an improvement in the number of correctly recorded drug intervals and frequencies when using the Slide. It is proposed this reflects the clarity of prescribing information presented on the outer sleeve.

Parents may administer an incorrect drug volume even after a correct dose has been calculated with only $30 \%$ of caregivers able to calculate and demonstrate an accurate dose for their child (16). Although teaspoons are the most commonly used domestic measuring device $(15,19)$, the volume of individual teaspoons is variable and may result in parents administering only $62 \%$ of the recommended dose (19). Previous studies have shown that caregivers are significantly more likely to measure an accurate drug volume using an oral syringe compared with a dosing cup or spoon with $63 \%$ of parents believing an oral syringe easy to use $(15,21)$. It is proposed that the precise values displayed on the Slide encouraged a greater number of parents in group 
2 to choose an oral syringe. The use of this more accurate measuring device did not impede parental ability to demonstrate drug volume and the reduction in dose error reported was therefore not at the expense of administration accuracy.

All Slide doses are calculated by weight and are within marketing authorisation to minimise adverse events (22). Weight based exact dose calculations may result in difficult to administer drug volumes and it has been proposed that prescribing easily measured practical dose weights alongside drug volume may assist in the recognition of errors (23). This principle was applied when calculating Slide doses and following British National Formulary for children $(\mathrm{BNFc})$ recommendations, the range of volumes presented on the Slide ( 6 to $10 \mathrm{ml}$ to an accuracy of $0.5 \mathrm{ml}$ ) can be accurately measured using a $5 \mathrm{ml}$ oral syringe with $0.5 \mathrm{ml}$ divisions (24). The National Patient Safety Agency has extended this concept and recommends that primary care dispensers additionally supply 1 and $10 \mathrm{ml}$ oral syringes when required to facilitate accurate administration of more complex medication regimens (25).

When considering paracetamol's inter-individual pharmacokinetic and analgesic variability it may be considered that such dose precision is unnecessary $(26,27)$ with rounding of administration volume to an accuracy of $2.5 \mathrm{ml}$ a logical suggestion (23). It is proposed however that presenting parents with a choice of doses through a range of volumes may lead to confusion or an overly relaxed attitude to drug administration. When Calpol's product information leaflets are analysed it is possible for a 1 to 6 year old child (10 to $20 \mathrm{~kg}$ ) to receive between 24 and $96 \mathrm{mg} / \mathrm{kg} /$ day depending on the child's actual weight and parental choice of drug volume (28). The BNFc quotes an unlicensed 'severe pain' paracetamol dose of up to $90 \mathrm{mg} / \mathrm{kg} /$ day with caution on use 
beyond 48 hours unless adverse effects have been ruled out (24). The highest deliverable domestic dose therefore exceeds that considered safe for use in a monitored in-patient environment. The median dose of paracetamol recommended on the Slide is $57.6 \mathrm{mg} / \mathrm{kg} /$ day with all regimens delivering less than $60 \mathrm{mg} / \mathrm{kg} / \mathrm{day}$; the maximum weight-based dose advised when adverse effects have not been ruled out (24). Parental response to the four statements suggests a high level of satisfaction in first time users of the Paediatric Analgesia Wheel and it is proposed that familiarity would result in an improvement in response to statement three.

The main limitation of the Slide is related to its use in children whose actual body weights deviate from ideal. The Slide is consistent with the BNFc and advises parents to use ideal body weight in overweight children although distinction is not made between an overweight or obese child and a child with a high body weight but an appropriately matched height (24). Ideal body weights, calculated as the mean from boys and girls $50 \%$ centile values on child growth charts (29), are displayed on the Slide alongside age to guide parents in choosing the correct drug volume. Despite this additional information there were 34 parents in group 2 who failed to correctly follow the Slide alignment instructions with resultant doses other than ideal recorded. Alignment failure was not dependant on whether the child's weight was ideal or not and this implies a failure in the presentation or interpretation of the Slide alignment information. The effect of these alignment errors was not large enough to prevent a reduction in dose error occurring in group 2 and it is proposed that further improvements could be made with clearer instructions. A second limitation arises from the exclusion of drug administration information for children under one-year. Therapeutic errors at home are more likely to occur in infants $(10,14)$ and further 

analysis. occurring.

research is required to ensure caregivers are able to calculate and demonstrate smaller drug volumes rather than extrapolating the results presented. A third limitation is that the Slide may give parents excessive confidence and may lead to paracetamol overdose if poorly labelled over-the-counter multi-component formulations are concurrently administered. A recent Food and Drug Administration Code of Federal Regulation has provided additional guidance to improve the quality of over-thecounter drug product labelling (30) and it is essential that the sleeve of the Slide is used to highlight additional drug safety information to minimise the risk of errors .
Acknowledgements: Mr Peter Gedling, Clinical Audit Analyst at County Durham and Darlington Acute Hospitals NHS Foundation Trust provided advice on statistical




\section{REFERENCES}

1. Homer JJ, Swallow J, Semple P. Audit of pain management at home following tonsillectomy in children. The Journal of Laryngology and Otology 2001;115:205-8.

2. Wilson ME, Helgadóttir HL. Patterns of pain and analgesic use in 3- to 7-yearold children after tonsillectomy. Pain Manag Nurs 2006;7:159-66.

3. Kankkunen P, Vehvilainen-Julkunen K, Pietila AM et al. Parents' perceptions and use of analgesics at home after children's day surgery. Paediatr Anaesth $2003 ; 1: 132-40$.

4. Taddio A, Goldbach M, Ipp M et al. Effects of neonatal circumcision on pain responses during vaccination in boys. Lancet 1995;345:291-2.

5. Taddio A, Katz J, Ilersich AL et al. Effects of neonatal circumcision on pain response during subsequent routine vaccination. Lancet 1997;349:599-603.

6. Clarkson A, Choonara I. Surveillance for fatal suspected adverse drug reactions in the UK. Arch Dis Child 2002;87:462-6.

7. Miles FK, Kamath R, Dorney SFA et al. Accidental paracetamol overdosing and fulminant hepatic failure in children. Med J Aust 1999;171:472-5.

8. Heubi JE, Barbacci MB, Zimmerman HJ. Therapeutic misadventures with acetaminophen: hepatotoxicity after multiple doses in children. $J$ Pediatr 1998;132:22-7.

9. Rivera-Penera T, Gugig R, Davis J et al. Outcome of acetaminophen overdose in pediatric patients and factors contributing to hepatotoxicity. $J$ Pediatr 1997;130:300-4. 
10. Tzimenatos L, Bond GR. Severe injury or death in young children from therapeutic errors: a summary of 238 cases from the American Association of Poison Control Centres. Clinical Toxicology 2009;47:348-54.

11. Hixson R, Gandhi M, Holton F. A randomised trial to evaluate prescribing accuracy when using the Paediatric Analgesia Wheel. Arch Dis Child 2009;94:268-72.

12. Hixson R, Hamilton M. An audit to evaluate the introduction of the Paediatric Analgesia Wheel into clinical practice at Darlington Memorial Hospital. Darlington and County Durham Medical Journal 2008/9;2(2):27-34.

13. Goldman RD, Scolnik D. Underdosing of acetaminophen by parents and emergency department utilization. Pediatr Emergency Care 2004;20:89-93.

14. Li SF, Lacher B, Crain EF. Acetaminophen and ibuprofen dosing by parents. Pediatr Emerg Care 2000;16:394-7.

15. Madlon-Kay DJ, Mosch FS. Liquid medication dosing errors. J Fam Pract 2000;49:741-4.

16. Simon HK, Weinkle DA. Over-the-counter medications. Do parents give what they intend to give? Arch Pediatr Adolesc Med 1997;151:654-6.

17. Shaoul R, Novikov J, Maor I et al. Silent acetaminophen-induced hepatotoxicity in febrile children: does this entity exist? Acta Paediatr 2004;93:618-22.

18. Morton NS, Arana A. Paracetamol-induced fulminant hepatic failure in a child after 5 days of therapeutic doses. Paediatr Anaesth 1999;9:463-5.

19. Hyam E, Brawer M, Harman J et al. What's in a teaspoon? Underdosing with acetaminophen in family practice. Fam Pract 1989;6:221-3. 
20. Patel VL, Branch T, Arocha JF. Errors in interpreting quantities as procedures: The case of pharmaceutical labels. International Journal of Medical Informatics 2002;65:193-211.

21. Sobhani P, Christopherson J, Ambrose PJ et al. Accuracy of oral liquid measuring devices: comparison of dosing cup and oral dosing syringe. Ann Pharmacother 2008;42:46-52.

22. Turner S, Nunn AJ, Fielding K et al. Adverse drug reactions to unlicensed and off-label drugs on paediatric wards: a prospective study. Acta Paediatr 1999;88:965-8.

23. McMillan C, Young SM, Anderson BJ. Practicality of dose prescriptions in a paediatric intensive care unit. Paediatric and Perinatal Drug Therapy 2007;8:96-100.

24. Paediatric Formulary Committee. BNF for Children [2008]. London: BMJ Publishing Group Ltd, RPS Publishing and RCPCH Publications; 2008.

25. National Patient Safety Agency. Promoting safer measurement and administration of liquid medicines via oral and other enteral routes, 2007. www.npsa.nhs.uk/patientsafety/alerts-and-directives/alerts/liquid-medicines (accessed 9 Aug 2009).

26. Anderson BJ, van Lingen RA, Hansen TG et al. Acetaminophen developmental pharmacokinetics in premature neonates and infants: a pooled population analysis. Anesthesiology 2002;96:1336-1345.

27. Anderson BJ, Woollard GA, Holford NHG. Acetaminophen analgesia in children: placebo effect and pain resolution after tonsillectomy. Eur J Clin Pharmacol 2001;57:559-569. 
1

3

4

5

6

7

8

9

10

11

28. Datapharm Communications Limited. The electronic Medicines Compendium. $\underline{\text { http://emc.medicines.org.uk/searchresults.aspx } ? \text { term }=\text { CALPOL\&searchtype }=Q}$ uickSearch (accessed 4 Jan 2010).

29. Child Growth Foundation (Charity Reg No 274325). Boys and Girls Growth Charts (Birth-18 years). London: 2 Mayfield Avenue, W4 1PW, 1996.

30. FDA U.S. Food and Drug Administration. Code of Federal Regulations Title 21, Subpart C--Labelling Requirements for Over-the-Counter Drugs revised as of April 1, 2009 (21CFR201.66).

http://www.accessdata.fda.gov/scripts/cdrh/cfdocs/cfcfr/CFRSearch.cfm?FR=20 1.66 (accessed 4 Jan 2010). 
Table 1. Primary, secondary and additional data analysis.

\begin{tabular}{|c|c|c|c|}
\cline { 2 - 4 } \multicolumn{1}{c|}{} & Group 1 (n=80) & Group 2 (n=80) & p value \\
\hline Median absolute percentage dose error & 33.3 & 0 & $<0.001$ \\
\hline $\begin{array}{c}\text { Number of correct dosage intervals and } \\
\text { frequencies }\end{array}$ & 59 & 70 & 0.046 \\
\hline $\begin{array}{c}\text { Number of correctly demonstrated drug } \\
\text { volumes }\end{array}$ & 77 & 70 & 0.082 \\
\hline $\begin{array}{c}\text { Number of parents who chose an oral } \\
\text { syringe to demonstrate drug volume }\end{array}$ & 24 & 44 & 0.002 \\
\hline
\end{tabular}

Absolute percentage dose error (primary endpoint) analysed using the Mann-Whitney $\mathrm{U}$ test. Secondary and additional endpoints analysed using the chi-squared test. 
3

4

5

6

7

8

9

Table 2. Weight and dose distribution for children whose parents completed the study using the Parental Analgesia Slide $(\mathrm{n}=80)$.

\begin{tabular}{|c|c|c|c|c|}
\cline { 3 - 5 } \multicolumn{2}{c|}{} & \multicolumn{3}{c|}{ Weight of child } \\
\cline { 3 - 5 } \multicolumn{2}{c|}{} & Ideal & Under & Over \\
\hline \multirow{2}{*}{\begin{tabular}{c} 
Dose recorded by $\begin{array}{c}\text { seal } \\
\text { parent }\end{array}$ \\
\cline { 2 - 5 }
\end{tabular}} & Ideal & 17 & 5 & 24 \\
\cline { 2 - 5 } & Under & 4 & 0 & 4 \\
\hline
\end{tabular}

Doses marked as 'ideal' are a result of correct alignment of the Slide for the age and weight of the child. The number of parents who did not align the Slide correctly with a resultant under or overdose is represented by the shaded area. The number of parents who failed to adjust the Slide correctly for a child with ideal body weight was compared with the number who failed when their child was either under or overweight using the chi-squared test. 
Figure 1. The Parental Analgesia Slide prototype.

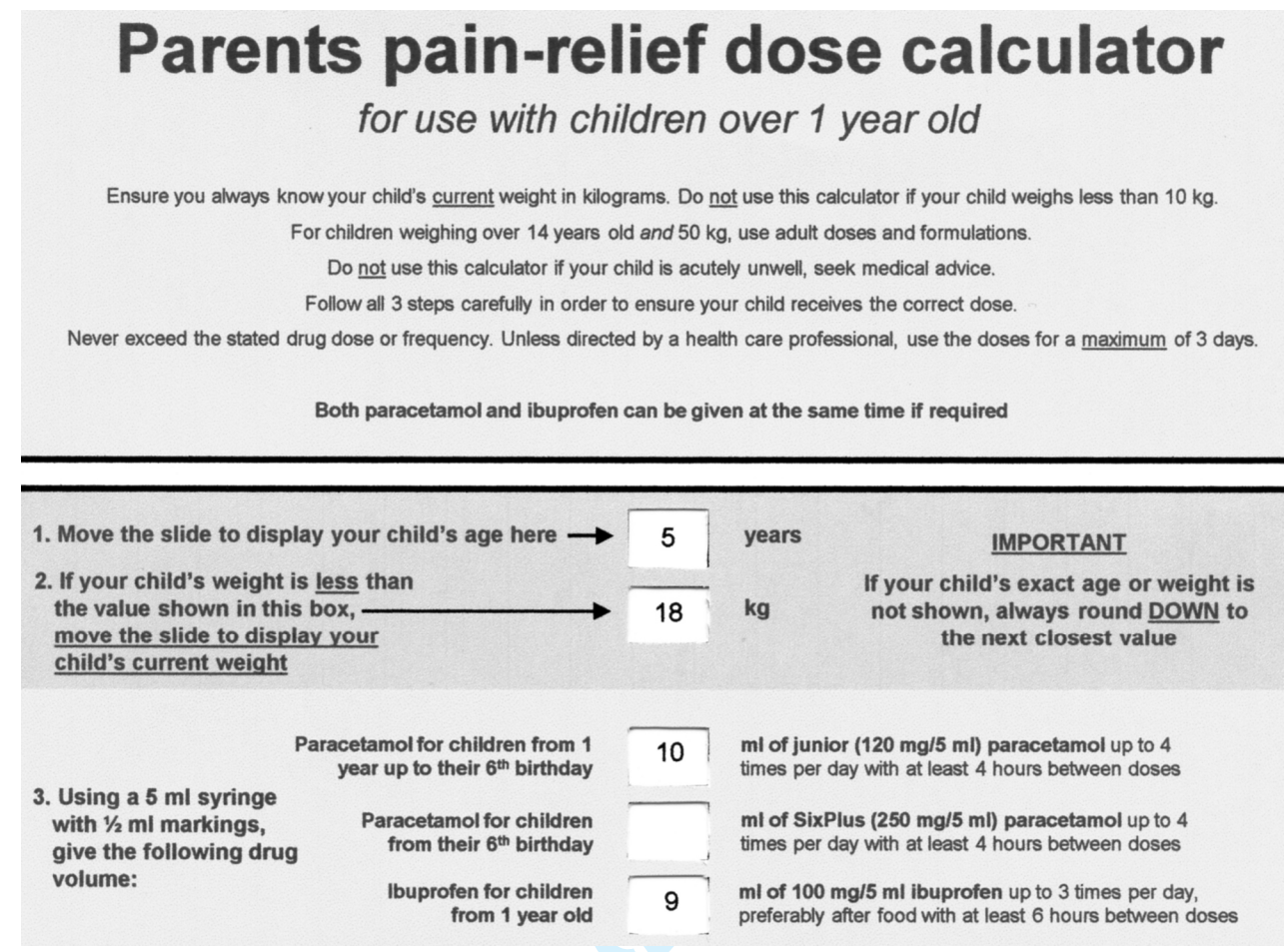

Figure showing both front and rear sleeves of the prototype. Doses on the Slide for a child of 5 years $/ 18 \mathrm{~kg}$ are visible through the cut-outs on the rear sleeve. During construction the Slide is sandwiched between the two sleeves shown. 


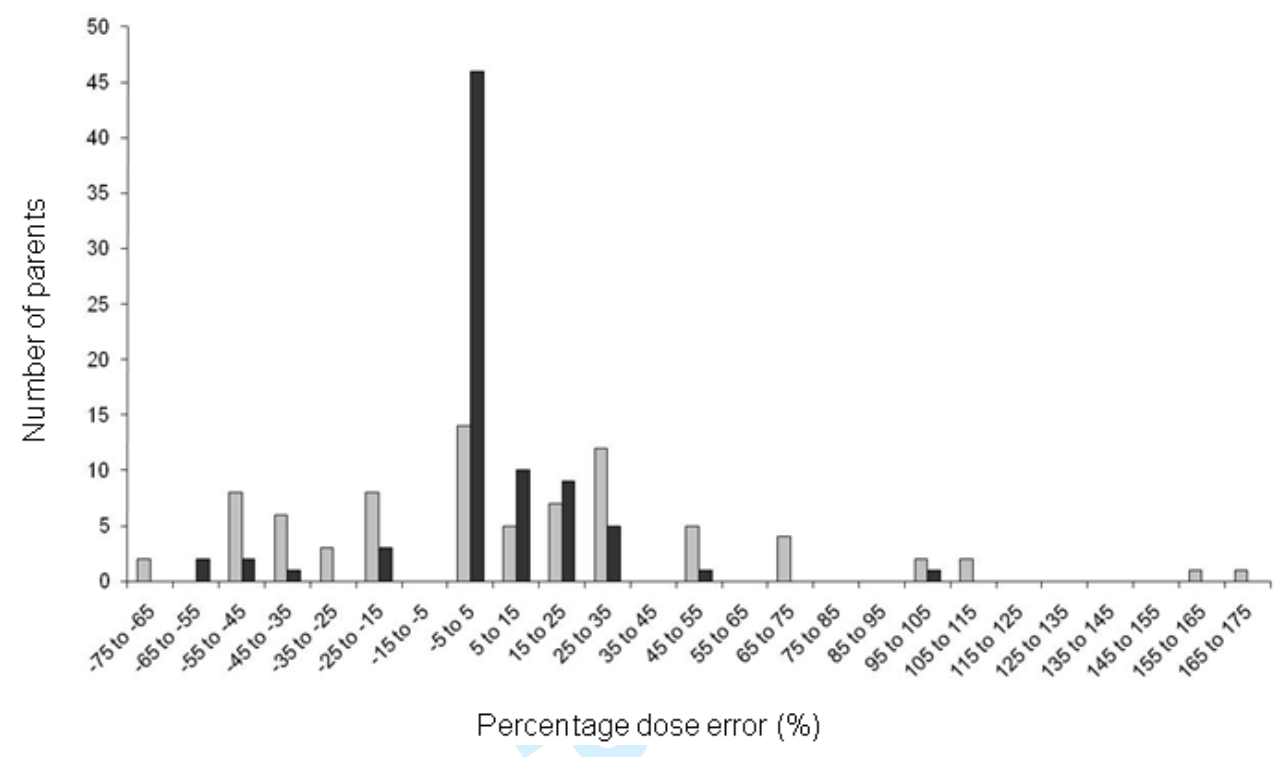

Distribution of percentage dose errors about ideal dose is displayed for the two groups before conversion to absolute values for analysis. Negative dose errors represent an under dose and positive dose errors an overdose compared with ideal dose $\pm 5 \%$. 
Figure 3. Parental responses to 4 statements following use of the Parental Analgesia Slide.

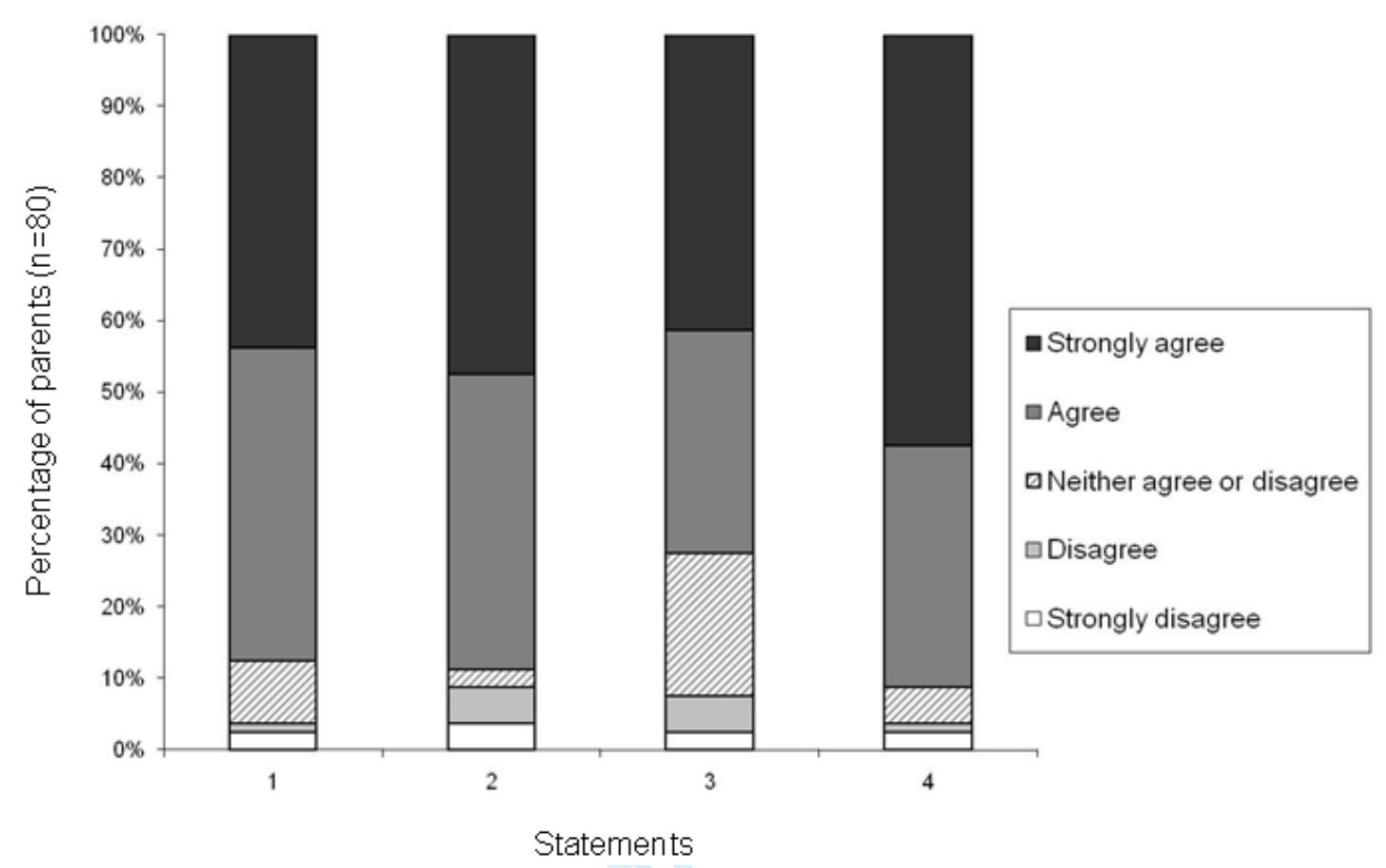

1. I think the new device is a good idea.

2. If available I would keep the new device at home and use when necessary.

3. I felt more comfortable calculating the amount of the drug to give when using the new device compared to when I normally administer paracetamol to my child.

4. I think the new device should be given away free by hospitals, GP surgeries and pharmacies.

Parental responses to the four questions presented on completion of the participant answer sheet after using the Parental Analgesia Slide (group 2). The percentage of parental responses are displayed for the 5 potential answers of strongly disagree to strongly agree. 

Items to include when reporting a randomized trial

\begin{tabular}{|c|c|c|c|}
\hline $\begin{array}{l}\text { PAPER SECTION } \\
\text { And topic }\end{array}$ & Item & Descriptor & $\begin{array}{l}\text { Reported on } \\
\text { Page \# }\end{array}$ \\
\hline TITLE \& ABSTRACT & 1 & $\begin{array}{l}\text { How participants were allocated to interventions (e.g., "random allocation", } \\
\text { "randomized", or "randomly assigned"). }\end{array}$ & 1,2 \\
\hline $\begin{array}{l}\text { INTRODUCTION } \\
\text { Background }\end{array}$ & 2 & Scientific background and explanation of rationale. & 2,3 \\
\hline $\begin{array}{l}\text { METHODS } \\
\text { Participants }\end{array}$ & 3 & $\begin{array}{l}\text { Eligibility criteria for participants and the settings and locations where the } \\
\text { data were collected. }\end{array}$ & 3 \\
\hline Interventions & 4 & $\begin{array}{l}\text { Precise details of the interventions intended for each group and how and } \\
\text { when they were actually administered. }\end{array}$ & 3 \\
\hline Objectives & 5 & Specific objectives and hypotheses. & 3,4 \\
\hline Outcomes & 6 & $\begin{array}{l}\text { Clearly defined primary and secondary outcome measures and, when } \\
\text { applicable, any methods used to enhance the quality of measurements (e.g., } \\
\text { multiple observations, training of assessors). }\end{array}$ & 3,4 \\
\hline Sample size & 7 & $\begin{array}{l}\text { How sample size was determined and, when applicable, explanation of any } \\
\text { interim analyses and stopping rules. }\end{array}$ & 4 \\
\hline $\begin{array}{l}\text { Randomization -- } \\
\text { Sequence generation }\end{array}$ & 8 & $\begin{array}{l}\text { Method used to generate the random allocation sequence, including details of } \\
\text { any restrictions (e.g., blocking, stratification) }\end{array}$ & 3,4 \\
\hline $\begin{array}{l}\text { Randomization -- } \\
\text { Allocation concealment }\end{array}$ & 9 & $\begin{array}{l}\text { Method used to implement the random allocation sequence (e.g., numbered } \\
\text { containers or central telephone), clarifying whether the sequence was } \\
\text { concealed until interventions were assigned. }\end{array}$ & 3,4 \\
\hline $\begin{array}{l}\text { Randomization -- } \\
\text { Implementation }\end{array}$ & 10 & $\begin{array}{l}\text { Who generated the allocation sequence, who enrolled participants, and who } \\
\text { assigned participants to their groups. }\end{array}$ & 3,4 \\
\hline Blinding (masking) & 11 & $\begin{array}{l}\text { Whether or not participants, those administering the interventions, and those } \\
\text { assessing the outcomes were blinded to group assignment. If done, how the } \\
\text { success of blinding was evaluated. }\end{array}$ & 3,4 \\
\hline Statistical methods & 12 & $\begin{array}{l}\text { Statistical methods used to compare groups for primary outcome(s); Methods } \\
\text { for additional analyses, such as subgroup analyses and adjusted analyses. }\end{array}$ & 4 \\
\hline $\begin{array}{c}\text { RESULTS } \\
\text { Participant flow }\end{array}$ & 13 & $\begin{array}{l}\text { Flow of participants through each stage (a diagram is strongly } \\
\text { recommended). Specifically, for each group report the numbers of } \\
\text { participants randomly assigned, receiving intended treatment, completing the } \\
\text { study protocol, and analyzed for the primary outcome. Describe protocol } \\
\text { deviations from study as planned, together with reasons. }\end{array}$ & 4,5 \\
\hline Recruitment & 14 & Dates defining the periods of recruitment and follow-up. & 4 \\
\hline Baseline data & 15 & Baseline demographic and clinical characteristics of each group. & N/A \\
\hline Numbers analyzed & 16 & $\begin{array}{l}\text { Number of participants (denominator) in each group included in each analysis } \\
\text { and whether the analysis was by "intention-to-treat". State the results in } \\
\text { absolute numbers when feasible (e.g., } 10 / 20 \text {, not } 50 \%) \text {. }\end{array}$ & 4,5 \\
\hline $\begin{array}{l}\text { Outcomes and } \\
\text { estimation }\end{array}$ & 17 & $\begin{array}{l}\text { For each primary and secondary outcome, a summary of results for each } \\
\text { group, and the estimated effect size and its precision (e.g., 95\% confidence } \\
\text { interval). }\end{array}$ & 4,5 \\
\hline Ancillary analyses & 18 & $\begin{array}{l}\text { Address multiplicity by reporting any other analyses performed, including } \\
\text { subgroup analyses and adjusted analyses, indicating those pre-specified and } \\
\text { those exploratory. }\end{array}$ & 5 \\
\hline Adverse events & 19 & All important adverse events or side effects in each intervention group. & N/A \\
\hline $\begin{array}{l}\text { DISCUSSION } \\
\text { Interpretation }\end{array}$ & 20 & $\begin{array}{l}\text { Interpretation of the results, taking into account study hypotheses, sources of } \\
\text { potential bias or imprecision and the dangers associated with multiplicity of } \\
\text { analyses and outcomes. }\end{array}$ & $5,6,7$ \\
\hline Generalizability & 21 & Generalizability (external validity) of the trial findings. & 6,7 \\
\hline Overall evidence & 22 & General interpretation of the results in the context of current evidence. & 6,7 \\
\hline
\end{tabular}

From Moher D, Schulz KF, Altman DG. The CONSORT statement: revised recommendations for improving the quality of reports of parallel-group randomised trials. Lancet 2001; 357(9263):1191-1194.

The CONSORT Statement 2001 checklist is intended to be accompanied with the explanatory document that facilitates its use. For more information, visit www.consort-statement.org. 


\section{The Consort E-Flowchart Aug. 2005}

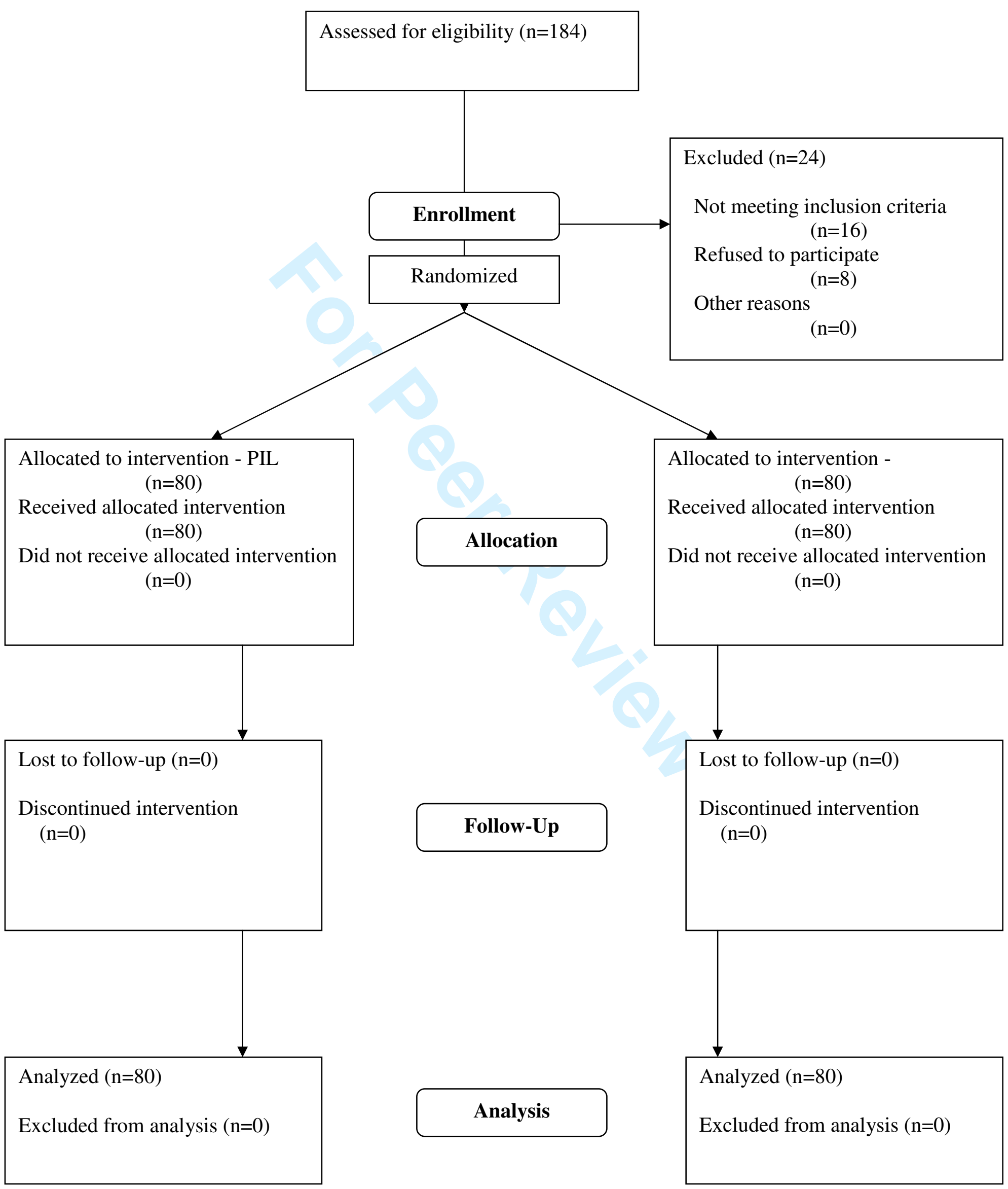




\title{
County Durham WHS and Darlington
}

\author{
NHS Foundation Trust
}

\section{Department of Anaesthesia}

\section{To evaluate the Paediatric Analgesia Slide, a new device developed to assist parents in administering paracetamol to children at home}

\author{
Protocol and background to the study, version 1.2, December 2008
}

Dr Richard Hixson

\section{TITLE}

To evaluate a new device developed to promote accurate and effective administration of paracetamol to children at home.

\section{INTRODUCTION}

\section{Background}

The National Service Framework for Children and Young People states that although medication errors in children occur at a similar rate to that in adults, the errors are three times as likely to cause harm. Reference is made to poor prescribing of analgesics with undertreatment of pain still a widespread problem.

There is published evidence that children do not receive adequate pain relief post-operatively when discharged from hospital. Parents seem reluctant or unwilling to give the necessary dose or frequency of analgesics despite instructions. In other cases, misinterpretation of prescribing information has led to errors resulting in serious adverse outcome or even death.

When prescribing information is examined, it is easy to see how problems occur. Age-range prescribing advice is presented in both the British National Formulary for Children (BNFc) and on the Patient Information Leaflet (PIL). This broad approach to providing prescribing and administration information has the potential for administered doses ranging from ineffective to the potentially dangerous depending on the age and weight of the child.

Previous research undertaken by the author has revealed that the use of a simple prescribing aide, the Paediatric Analgesia Wheel (figure 1) can improve the accuracy of prescriptions made by hospital doctors. This research was presented at the Association of Paediatric Anaesthetists 2008 Annual Scientific Meeting. It is suggested that the principle of this hospital-based device may be extended into the community to facilitate the accurate administration of paracetamol to children at home.

The new device under evaluation has been developed to provide clear drug administration information for parents. The device gives the volume of paracetamol to administer to children aged between 1 and 13 years ( 10 to $44 \mathrm{~kg}$ ). The volumes recommended can easily and accurately be administered using a $5 \mathrm{ml}$ oral syringe with $1 / 2 \mathrm{ml}$ divisions or a $5 \mathrm{ml}$ measuring spoon. 13 years was chosen as the upper age limit since a 14 year old (ideal body weight 50 $\mathrm{kg}$ ) is likely to receive an adult dose regimen.

In order to further develop this idea, it is important to establish whether the device can successfully deliver this information to parents and improve the accuracy of drug 
administration. It is therefore proposed to research this device using volunteers (parents) attending County Durham and Darlington Acute Hospitals NHS Trust.

It is proposed that the device will improve upon the drug dose the child would have received compared to the using the PIL found in the boxes of over-the-counter paracetamol.

\section{METHODS}

\section{Design}

Prospective, randomized study comparing the ideal dose of paracetamol with that prescribed by parents when using either the PIL for paracetamol or a new prescribing device, the Paediatric Analgesia Slide (known hereafter as the 'device' or the 'new device').

\section{Participants}

For the purpose of this study, the term parent is used to define an individual who has parental responsibility. Volunteers will be sought from parents accompanying their children who are attending County Durham and Darlington Acute Hospitals NHS Trust. Parents to be excluded from the study will be:

- those who have professional knowledge of prescribing or dispensing medicine (e.g. as a doctor, nurse or pharmacist);

- those who already have been given advice on the correct dose of paracetamol for their child as part of the current hospital episode;

- those who's child is under 1 year or over 13 years old and;

- those who have participated in this research before.

Volunteers will be approached by one of the named data collectors. When more than one parent is present, only one may complete the test and parents may not confer. This is to ensure consistency of data collection independent of the number of parents present. Recruitment is planned to take place between December $1^{\text {st }}, 2008$ and $31^{\text {st }}$ May, 2009.

\section{Interventions}

Participants will be required to read the Participant Information Sheet describing the background to the study. Once this sheet has been read, the participant will then have the opportunity to ask questions. Once questions have been answered, the participant will be required to sign a Consent Form agreeing to inclusion in the research. Both methods of completing the exercise will be explained fully to the participant at this stage. This is to ensure bias does not occur in the level of explanation once the method of completing the exercise has been revealed. In order to avoid one method of dose calculation influencing the data obtained from the second method, participants will be randomly allocated to complete the test using only one of the two methods.

The envelope containing the Participant Instruction and Answer Sheet will be opened revealing which method the participant is required to use in deciding the volume of paracetamol they would administer to their child post-operatively. The participant will be asked to read this document fully and final questions will be answered. The 2 methods of completion will be either:

- using the PIL that has been obtained from over-the-counter boxes of paracetamol of both the 'junior' $(120 \mathrm{mg} / 5 \mathrm{ml})$ and $6^{+}(250 \mathrm{mg} / 5 \mathrm{ml})$ formulations or;

- calculation of volume based upon the prescribing information presented on the new device. The participant will have the opportunity to read the instructions displayed on the device before attempting to use it for the first time.

Using their child's age and weight plus the information on the PIL or the new device, the participant will be required to state the formulation and the volume of paracetamol they would administer to their child. In addition, the parent will be asked how many times they would 
administer the dose per day and the minimum interval (in hours) between doses. All this information is clearly stated in the PIL and on the new device. The participant will then be asked to demonstrate, using either a $21 / 2$ / $5 \mathrm{ml}$ dosing spoon or a $5 \mathrm{ml}$ syringe with $1 / 2 \mathrm{ml}$ divisions, their ability to actually measure the volume they have stated. Further information on the parent's educational attainment (as defined by the Office for National Statistics) will be collected to ascertain whether the two groups of parents are educationally similar in their composition.

\section{Objectives and outcomes}

The primary objective is to compare the 2 groups with respect to the absolute percentage dose-error resulting from the volume (and therefore dose) administered compared to the weight-specific 'ideal' dose calculated by the researchers as documented below in the statistical analysis section. The 2 groups will be compared to ascertain which method results in the administration of a dose closest to the ideal (e.g. the lowest absolute percentage dose error). Use of the absolute value focuses the analysis on the magnitude of the dose error. Although it may be of interest to examine the direction of error (over or under-dose), the researchers feel that it is the potential reduction in the magnitude of dose-error that is the highest priority for this new device.

The secondary objectives are:

- to analyse the data relating to maximum dosage frequency in 24 hours and minimum interval between doses. The 2 groups will be compared to ascertain whether one group provides more correct answers for this question and;

- to analyse the ability of the participant to actually measure the volume they would choose to give. The 2 groups will be compared to ascertain whether one group provides more correct answers for this question.

The null hypothesis for the primary endpoint analysis is that there is no benefit in using the new device and there will be no difference in the absolute PDE when comparing the two groups. The alternative hypothesis is that one method is superior to the other, with a significant difference in the absolute PDE.

The null hypothesis for the two secondary objectives is that there will be no difference in the proportion of correct answers obtained when comparing the 2 groups. The alternative hypothesis is that one method will result in a greater proportion of correct answers.

\section{Sample size}

Sample size estimation was based on the ability of the study to detect a difference of $10 \%$ in the mean absolute percentage dose error between the two methods. A pilot study gave a mean (sd) absolute percentage dose error of $17.5 \%$ (23.7) for the PIL method. It was assumed that the mean absolute percentage dose error would be reduced to $7.5 \%$ by the new method. From this it was calculated that 70 individuals would be required in each group to have an $80 \%$ chance of achieving a significant difference in mean absolute percentage dose-error. Adjustment for non-parametric data and use of the Mann-Whitney U test through application of asymptotic relative efficiency, results in the need for an additional $15 \%$ participants resulting in a total of 80 in each group.

\section{Randomization, data collection and entry}

170 Participant Instruction and Answer sheets will be generated by the data entry researcher. These forms will either be marked 'PIL' or 'new device' on the front page with each group represented in equal numbers. These will then be sealed in identical envelopes and shuffled. These envelopes will then be handed to the data collection researcher who will be unaware of the contents. These will be handed out sequentially to participants. Although 160 individuals are required based upon the power calculation, 170 forms will be generated to counter the effects of participant withdrawal that may result in an under-powered study. Data collection will continue until 160 forms have been completed. 
Volunteers will be tested only once to ensure there is no memory effect that may invalidate the data. Volunteers can withdraw at any stage without penalty. Once the test is complete, volunteers who have used the new device will have the opportunity to comment using a simple rating scale in response to 4 statements. This will enable the designers to gain objective insight into the opinion of the potential users.

Written information obtained will be handed over to the data analysis researcher who will enter the collected data onto the results spreadsheet. From the volume and formulation, dose will be calculated. The answers related to maximum dosage frequency (MDF) and minimum dosage interval (MDI) will be scored as either correct or incorrect as compared to the information contained within drug marketing authorisation. The demonstrated volume to administer will be compared to the written volume to administer and marked as either correct or incorrect. Only once the dose and deviation from ideal has been calculated and the questions related to the secondary objectives have been scored will the data analysis researcher access and record the method of completion.

The data will be entered into a spreadsheet contained on a secure password protected computer located within the lead researcher's office at Darlington Memorial Hospital. After data entry, all paper copies of the study data that may be linked with an individual will be destroyed.

\section{Blinding}

The data collection researcher will be unaware of the method of completion until the envelope is opened just before the test is undertaken. The data collection researcher is not responsible for data entry and analysis. The data analysis researcher will be unaware of the method of completion until the data has been scored and entry into the spreadsheet is complete (see randomisation). This blinding will eliminate potential bias of the data analysis researcher when calculating dose deviation from the ideal and scoring the questions related to the secondary objectives.

\section{Statistical methods}

For the purpose of this study, it is important to define the 'ideal dose' of paracetamol. This is a previously undefined quantity as is evident by published and widely accepted age-range dose regimens found in the Summaries of Product Characteristic, on the PILs and in the BNFc. For example, current age-range prescribing for paracetamol on the PIL (120 to $240 \mathrm{mg}$ for a 1 to 6 year old child) has the potential for both under and over-dosing depending on the exact age and weight of the child and the dose decided upon by the prescriber or administrator.

Therefore we define the ideal dose as one that:

- is based upon actual body weight but using ideal body weight in overweight children who's weight exceeds that expected for their age;

- is easily administered with available technology $\left(2 \frac{1}{2}\right.$ or $5 \mathrm{ml}$ spoon or $5 \mathrm{ml}$ syringe with $1 / 2 \mathrm{ml}$ divisions) and;

- is within the drugs marketing authorisation to ensure that adverse drug events are kept to a minimum.

In using the child's actual body weight and age, we introduce the potential for prescribing confusion that results from prescribing to children who's age and weight deviate from the ideal. This is however a real and frequently occurring problem that needs to be considered when prescribing to children. The BNFc is clear in its advice. When calculating dose, actual body weight should be used except when a child is overweight where ideal body weight should be used instead. This is not covered on the paracetamol PIL and therefore it will be of interest to see how the information is applied by parents under these circumstances. The new device presents clear information on how to administer paracetamol under these

circumstances and therefore it is hoped the new device will increase the likelihood of the ideal dose being prescribed. The ideal body weights for each age group has been calculated as an average of the boys and girls 50\% centile weights as displayed on the Boys and Girls Growth 
Charts (Birth-18 years), Child Growth Foundation 1996/1 (Charity Reg No 274325), 2 Mayfield Avenue, London W4 1PW.

The BNFc advises the use of weight to calculate doses. The unlicensed doses for severe pain advise $20 \mathrm{mg} / \mathrm{kg} /$ dose for in-patients but $15 \mathrm{mg} / \mathrm{kg} /$ dose for children receiving paracetamol for $>48$ hours continuous use when adverse effects cannot be excluded. This would therefore include use at home and therefore forms the basis for the calculation of actual dose.

This $\mathrm{mg} / \mathrm{kg}$ approach has therefore been applied to age-range prescribing with a gradation of doses depending on weight but keeping within the age-range marketing authorisation as specified in the PIL. In addition, the doses have been calculated to ensure administration is possible using a $5 \mathrm{ml}$ oral syringe with $1 / 2 \mathrm{ml}$ divisions. This is the only syringe that hospital doctors are able to prescribe for parents (BNFc 2007, p3). For example a child between 1 and 6 years can receive, according to the PIL for paracetamol, 120 to $240 \mathrm{mg} 4$ hourly, maximum 4 times per day. Therefore, an ideal dose of paracetamol would be:

\begin{tabular}{|c|c|c|c|}
\hline Age (years) & Weight $(\mathrm{kg})$ & Ideal dose $(\mathrm{mg})$ & Volume of $120 \mathrm{mg} / 5 \mathrm{ml}(\mathrm{ml})$ \\
\hline 1 & 10 & 144 & 6 \\
\hline $11 / 2$ & 11 & 156 & 6.5 \\
\hline 2 & 12 & 180 & 7.5 \\
\hline $21 / 2$ & 13 & 192 & 8 \\
\hline 3 & 14 & 204 & 8.5 \\
\hline $31 / 2$ & 15 & 216 & 10 \\
\hline 4 & 16 & 240 & 10 \\
\hline $41 / 2$ & 17 & 240 & 10 \\
\hline 5 & 18 & 240 & 10 \\
\hline 6 & 20 & 240 & \\
\hline
\end{tabular}

Since the PIL for paracetamol states 1 to 2 large $5 \mathrm{ml}$ spoonfuls for a 1 to 6 year child, it is likely that the child would receive either 5 or $10 \mathrm{ml}$. This may result in the 1 and 6 year old receiving the extreme of the dose options. For example a child receiving paracetamol four times a day may receive a wide range of potential doses when using the licensed PIL administration information:

\begin{tabular}{|c|c|c|c|c|}
\hline Age (years) & Weight $(\mathrm{kg})$ & $\begin{array}{c}\text { Volume }(\mathrm{ml}) \\
120 \mathrm{mg} / 5 \mathrm{ml} \text { solution }\end{array}$ & Dose $(\mathrm{mg})$ & Daily dose (mg/kg/day) \\
\hline 1 & 10 & 5 & 120 & 48 \\
\hline 1 & 10 & 10 & 240 & $96(\mathrm{high})$ \\
\hline 6 & 20 & 5 & 120 & $24(\mathrm{low})$ \\
\hline 6 & 20 & 10 & 240 & 48 \\
\hline
\end{tabular}

Therefore when using the PIL, a child of 1 year could receive an over-dose of $96 \mathrm{mg} / \mathrm{kg} / \mathrm{day}$ whereas a child of 6 years may receive a low dose of $24 \mathrm{mg} / \mathrm{kg} / \mathrm{day}$. Although these doses are permissible, they are not desirable since they range from the ineffective to an overdose. The BNFc is clear in stating that doses of $90 \mathrm{mg} / \mathrm{kg} /$ day should only be continued after 48 hours if 'adverse effects have been ruled out'. It is unlikely that when paracetamol is administered at home, adverse effects at 48 hours could be excluded. Therefore, as stated in the BNFc, the lower limit of $60 \mathrm{mg} / \mathrm{kg} / \mathrm{day}$ should be applied. This makes the potential 'PIL' dose of $96 \mathrm{mg} / \mathrm{kg} /$ day a serious risk to the younger child as is evident in the publications describing hepatic failure and death in children treated with such doses.

A similar scenario arises for a child between 6 and 12 years old receiving 250 to $500 \mathrm{mg}$. Ideal doses for this age-range would therefore be:

\begin{tabular}{|c|c|c|c|}
\hline Age (years) & Weight $(\mathrm{kg})$ & Ideal dose $(\mathrm{mg})$ & Volume of $250 \mathrm{mg} / 5 \mathrm{ml}(\mathrm{ml})$ \\
\hline 6 & 20 & 300 & 6 \\
\hline 7 & 23 & 325 & 6.5 \\
\hline 8 & 26 & 375 & 7.5 \\
\hline 9 & 28 & 400 & 8 \\
\hline
\end{tabular}




\begin{tabular}{|l|l|l|l|}
\hline 10 & 32 & 475 & 9.5 \\
\hline 11 & 35 & 500 & 10 \\
\hline 12 & 39 & 500 & 10 \\
\hline
\end{tabular}

The new device prevents these potential extremes of doses using the principles stated above.

Each volume stated by the participant will be converted to a dose that is dependent on the formulation used. The dose is then compared to the ideal dose based upon either the child's weight (or age in the overweight child equating to ideal body weight). The differences between the parental and the ideal doses will be calculated and expressed as percentages (the 'dose errors') to compensate for the variation in dose across the weight / age groups.

The percentage dose error will be converted to an absolute value which reflects the magnitude (not direction) of the error from ideal. This transformation of data automatically results in non-parametric data and therefore the 2 groups will be compared using the MannWhitney U-test.

Both maximum dosage frequency (MDF) and the minimum dosage interval (MDI) will be compared to that within the PIL (maximum 4 doses per day, 4 hours apart). The number of correct answers given in the 2 groups will be compared using the chi-squared test.

The demonstrated volume to administer will be compared to the written volume to administer and marked as either correct or incorrect. The number of correct answers in the 2 groups will be compared using the chi-squared test.

\section{RESULTS}

Immediate scrutiny of results by the data collection researcher will allow the identification of participants who, based upon the provided results, may administer an overdose to their child. The data collection researcher will point out the error immediately with full explanation of the error and the correct answer.

Additional data that may be presented includes:

- level of education attainment of parents within the 2 groups;

- participants interpretation of prescribing information found in the PILs and on the new device when faced with a child whose weight deviates from the ideal body weight;

- the number of prescriptions associated with over and under-dosing of paracetamol and;

- the participants opinion on the new device presented as the response to the 4 closed questions.

The research will be submitted to be considered for presentation at the 2010 Annual Scientific Meeting of the Association of Paediatric Anaesthetists of Great Britain and Ireland. It will also be submitted for consideration to be published in a peer review journal.

The researchers appreciate that superficially the research may appear to be self-fulfilling since the data on the new device is essentially the same as the data defined as 'ideal'. However since the device is new and unfamiliar to parents, it is not just the actual data that is important but the way in which the data is presented. The functionality of the device is being assessed with prescribing accuracy being used as the objective measure of function. If parental administration proves to be closer to the ideal when using the PIL, then the data presentation and functionality of the new device is not effective and will therefore need to be re-designed. 
Figure 1. The Paediatric Analgesia Wheel prototype (not final distributed product)

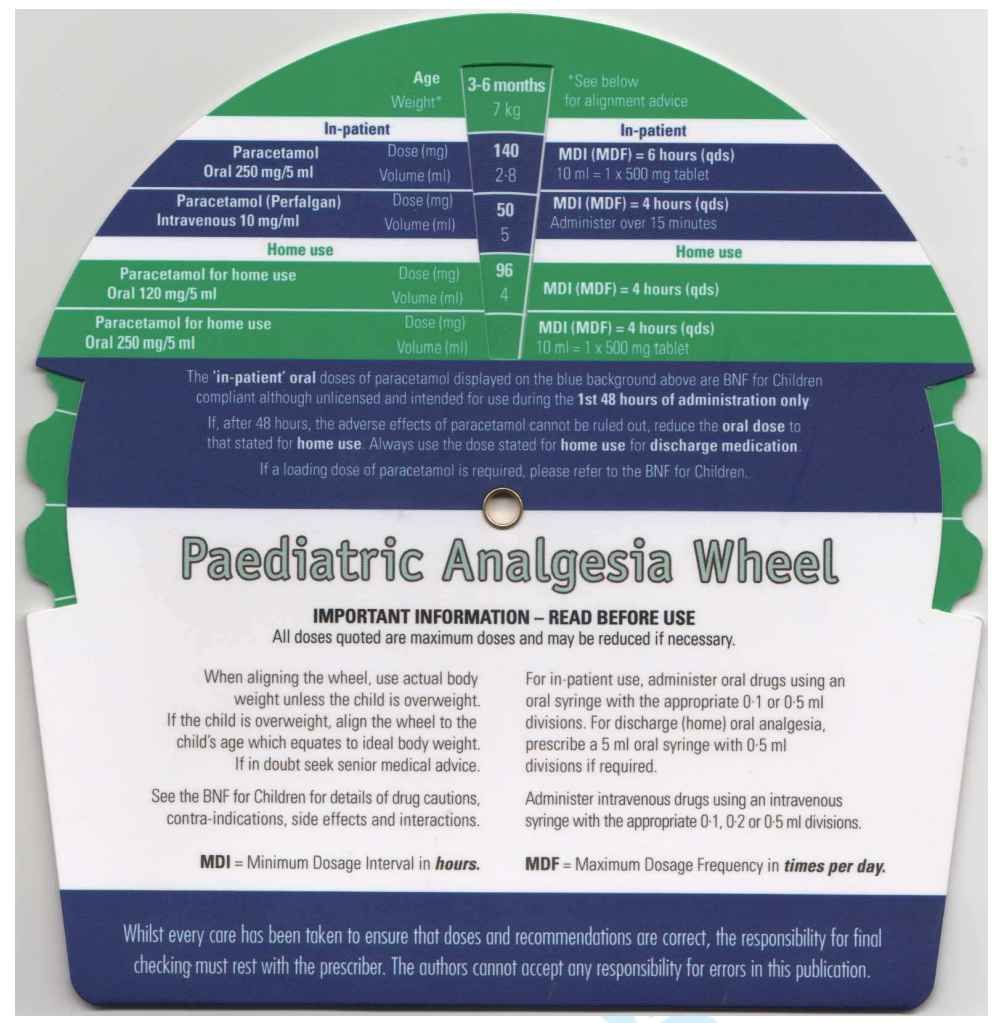

Figure 2. The Paediatric Analgesia Slide (The New Device)

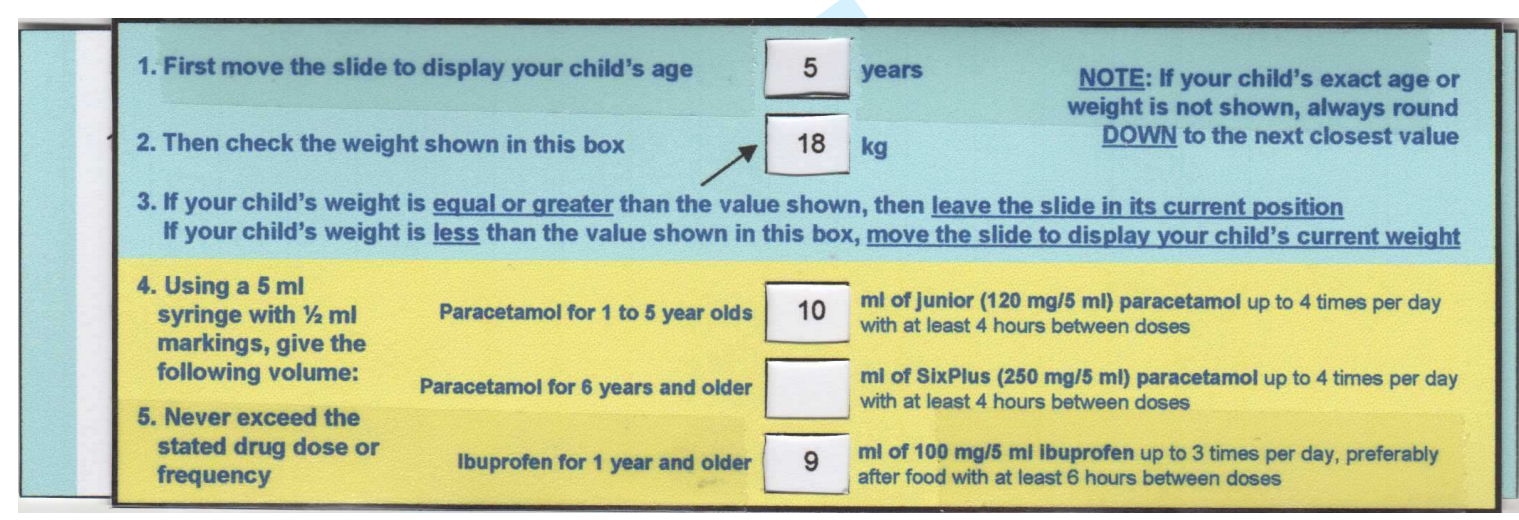




\section{County Durham WHS and Darlington \\ NHS Foundation Trust}

\section{To evaluate the Paediatric Analgesia Slide, a new device developed to assist parents in administering paracetamol to children at home}

\section{Participant Information Sheet}

Version 1.1 (December 2008)

You are invited to participate in a study to assess a new device designed to help parents administer an accurate dose of paracetamol to their children at home. The study will compare the dose you provide with an ideal dose calculated from prescribing information.

For the purposes of the research, your own child is the one receiving treatment in County Durham and Darlington Acute Hospitals NHS Foundation Trust. The term parent is used to define an individual who has parental responsibility.

You may not continue with this study if either:

- you have professional knowledge of prescribing or dispensing medicines (e.g. as a doctor, nurse or pharmacist);

- you have already been given advice on the correct dose of paracetamol for your child during this hospital admission;

- your child is under 1 year or over 13 years old or;

- you have participated in this study before. 
As a participant, you will be randomly allocated to complete the test using one of two methods. You will not know which method until both have been fully explained. You will then be given an envelope to open. The method of calculation will be either:

- using the information provided with the over-the-counter drug or;

- using a new device which provides pre-calculated drug information.

Using the information provided, you will be asked:

- what formulation and volume of paracetamol you would give your child;

- how many times per day you would give the drug;

- how many hours you would allow between doses and;

- to demonstrate with a syringe or spoon and some water (all provided), the actual volume you would administer.

If you are one of 2 parents present only one of you may complete the study and must do so without the help of the $2^{\text {nd }}$ parent. After completing the exercise, your answers will immediately be checked for accuracy. In the event of an answer that may lead to an overdose, you will be informed of this prior to leaving the study.

Additional information requested relates to your educational attainment. This is to ensure that the individuals completing the test are similar in both groups. Your answers along with your child's age and weight will be entered into a spreadsheet and your hand-written data will be destroyed. The spreadsheet data is kept on a secure password protected computer on hospital premises. You cannot be linked with this data and your anonymity is guaranteed.

The information you provide will be pooled for analysis and the two groups compared statistically to see whether one of the methods results in a more accurate dose of pain killers being given to children within the context of the study. 
Please ensure you read the Participant Instruction and Answer Sheet carefully before completing the test. After reading, feel free to ask questions of the investigator.

If you do not wish to proceed, please inform the investigator at this or any other point during the research. Any collected data will then be destroyed. If you agree to proceed, you will be asked to sign a consent form documenting that you agree to take part in the research.

In the event of you, the participant, requiring further information or counselling following your involvement in this study, this can be arranged at your request. In the event of any questions or comments relating to this study, you may call Dr Richard Hixson, Chief Investigator, on 07796204580.

Thank you for participating in this study,

Dr Richard Hixson

Consultant Anaesthetist

Lead Researcher
Dr's Uwe Franke, Mika Hamilton and Rohit Mittal

Specialist Trainees, Anaesthesia

Data Collection Researchers 


\title{
County Durham WHS and Darlington \\ NHS Foundation Trust
} To evaluate the Paediatric Analgesia Slide, a new device developed to
assist parents in administering paracetamol to children at home

\section{Participant Instruction and Answer Sheet}

Version 1.1 (Sept 2008)

\begin{abstract}
Before continuing, please ensure you have read and understood the Participant
Information Sheet and you have signed the Consent Form confirming your agreement to be included in this research. You should at this stage understand what is required of you and also understand the two possible methods of calculating the volume of paracetamol you would theoretically give your child.
\end{abstract}

Please read the following Participant Instruction Sheet carefully before completing the answers. After reading, feel free to ask questions of the investigator. Please ensure you understand the questions that can be found over the page. Only once you are happy will the investigator continue.

You will complete the exercise using the:

- Patient information leaflet

- The new device

Do you have a professional knowledge of prescribing or dispensing medicines?

Yes / No

Educational attainment, you have:

- a degree or degree-level vocational qualification, or above

- a qualification below degree level

- no educational or vocational qualifications

Please turn over...... 


\section{Data collection form}

Your child's age:

Your child's weight $(\mathrm{kg})$ :

For the purpose of completing the following questions, assume your child has just had an operation and is at home and requires paracetamol to be given by you.

I would use the following version (formulation) of paracetamol (please tick):

Infant suspension $\left(2^{+}\right.$months, $120 \mathrm{mg} / 5 \mathrm{ml}$ )

SixPlus suspension $\left(6^{+}\right.$years, $\left.250 \mathrm{mg} / 5 \mathrm{ml}\right)$

I would give the following volume (in $\mathrm{ml}$ or number of $2^{1 / 2}$ or $5 \mathrm{ml}$ spoonfuls) of the above formulation to my child whose age and weight is stated above:

I would give the above dose times per day allowing a minimum of hours between doses.

For the data collection researcher to complete: The demonstrated volume to administer was $\mathrm{ml}$ which consisted of (spoons or mls).

Thank you for participating, Dr Richard Hixson, Chief Investigator 


\title{
New device user opinion form
}

\begin{abstract}
If you have just used the new device for calculating the dose of paracetamol for your child, please take a moment of your time to complete the following:
\end{abstract}

\section{Please answer the following questions using a scale of:}

1. Strongly disagree

2. Disagree

3. No strong feelings

4. Agree

5. Strongly agree

Question 1:

Score:

I think the new device is a good idea.

Score:

Question 2:

If available, I would keep the new device at home and use when necessary.

Question 3:

Score:

I felt more comfortable calculating the amount of the drug to give when using the new device compared to when I normally administer paracetamol to my child.

Question 4:

Score:

I think the new device should be given away free by hospitals, GP surgeries and pharmacies.

Additional comments: 